\title{
Modelling Long Run Comovements in Equity Markets: a Flexible Approach
}

\author{
Luis F. MARTINS* \\ Department of Quantitative Methods and UNIDE, ISCTE-IUL, Portugal \\ VASCO J. GABRIEL \\ School of Economics, University of Surrey, UK and NIPE-UM, Portugal
}

March 2014

\begin{abstract}
International equity markets linkages are characterized by nonlinear dependence and asymmetries. We investigate shifts in long run comovements in stock markets by means of an 'interrupted' Markov switching cointegration specification. This flexible approach allow us to study to what extent documented changes in global integration are permanent, or whether market linkages are subject to changes. Using an illustrative sample from 1980 to 2012 for USA, UK and Hong Kong stock price indices, we find evidence of interrupted cointegration across these markets between May 1997 and April 2002, which is consistent with the decoupling of stock prices from fundamentals during the dot-com bubble.
\end{abstract}

Key Words: Financial Markets, Financial Integration, Long Run Analysis, Local Nonstationarity, Markov Switching.

JEL Classification: C22, C52,G15.

\footnotetext{
${ }^{*}$ Corresponding author. Address: UNIDE and Department of Quantitative Methods, ISCTE-LUI, Business School, Av. das Forças Armadas, 1649-026 Lisbon, Portugal. E-mail: luis.martins@iscte.pt. Tel: + 351217903439 . Fax: + 351217903941.
} 


\section{Introduction}

It seems to be now consensual that an important feature of globalisation and increased capital mobility has been the gradually integrated nature of financial markets. As a consequence, several issues arise. On the one hand, tighter cross-market financial linkages may lead to more efficient capital allocation, lower probability of asymmetric shocks and thus better conditions for economic development (see Umutlu, Akdeniz and Altag-Salih, 2010). On the other hand, growing financial interdependence increases the risk of financial contagion, in which shocks originating in one market can quickly spread to others due to (potentially episodic) intensified cross-market linkages. Furthermore, increased comovements may curtail national governments' ability to design appropriate stabilization policies.

Different explanations for the transmission of contagion effects have been put forward, ranging from information/news propagation effects affecting the balance sheet of firms holding assets in the troubled market (see King and Wadhwani, 1990 and Kiyotaki and Moore, 2002), a liquidity channel in which a flight-to-quality effect leads to liquidity shortages in integrated markets (see Allen and Gale, 2000, Kodres and Pritsker, 2002 and Brunnemerier and Pedersen, 2009, for example) or time-varying risk premiums, in which negative shocks in one market affects the willingness of agents to bear risk in other markets (see Acharya and Pedersen, 2005). Regardless of the propagation mechanism, it is clear that firmer market linkages and financial contagion may affect portfolio diversification, due to the equalization of returns, and thus endanger financial stability.

In this context, it is crucial to empirically reassess the evidence on equity markets comovements and to which extent different markets are integrated. We suggest in this paper that the degree of integration across equity markets is better viewed as time-varying. ${ }^{1}$ Here, rather than studying short run linkages, we choose to focus on long run integration of price levels (which are unlikely to be stationary) in a manner that captures the well known time-varying nature of international asset markets correlations. Thus, for this purpose, we suggest employing a class of single-equation 'interrupted' cointegration models in which we allow for (possibly) several periods out of equilibrium. The statistical law behind the generating break points is stochastic, the equilibrium term dynamics - modelled as an AR(1) - depending upon an unobserved state process that is a stationary first-order Markov chain in two states, stationarity and non-stationarity.

Once the least squares residuals of the equation in levels are obtained, the model is estimated and inference is conducted by means of likelihood methods. We employ Qu's (2007) tests for changes in cointegration rank, given their advantage over others of not having to specify any particular cointegration model and of allowing for more than one change over time in the cointegration rank.

Several other studies have considered cointegration methods in an attempt to uncover

\footnotetext{
${ }^{1}$ Alternative mechanisms may lie behind such nonlinearities on the long run relationship of stock prices: shifts in expectations leading to multiple equilibria due to expectation shifts, time-varying herd behaviour caused by changes in fundamentals, etc.
} 
whether or not a unifying force exists across markets, such that individual equity indices converge to some sort of long run equilibrium. Thus, deviations of one market away from the common trajectory are expected to be reversed in the long term - for example, if a market has performed above expectations, then a reversal should be expected in the future. ${ }^{2}$ The results, however, are mixed. Kasa (1992), Arshanapalli and Doukas (1993), Corhay, Tourani Rad and Urbain (1993), Chou, Ng and Pi (1994), Richards (1995) and Manning (2002), inter alia, applied Engle-Granger and Johansen cointegration methods, with results differing according to the method, the sample period and the markets considered.

In fact, one of the shortcomings of standard cointegration approaches is that it is assumed that cointegration will always exist and that the cointegrating vector(s) do not change over time, which is quite restrictive and does not take into account the well known variation in equity risk premia (see Campbell, 1987 and Bekaert and Harvey, 1995, for example; Haldane and Hall, 1991 tackle this issue using the Kalman filter, but not in a cointegration framework, studied by Aggarwal, Lucey and Muckley, 2004). Thus, modelling asset market integration without considering the time-varying nature of financial linkages may result in misleading conclusions. Our approach allows for more flexibility in studying the dynamics of financial integration and may therefore help to shed light on the contradictory findings in the literature.

We should note that there is a vast literature that investigates stock market linkages focusing mostly on cross-country correlations of asset returns. Several methods have been employed, ranging from standard GARCH models (Longin and Solnik, 1995), adjusted measures of correlation (Forbes and Rigobon, 2001 and 2002), switching ARCH methods (Ramchand and Susmel, 1998) or copula models (Rodriguez, 2007 and Garcia and Tsafack, 2011, for example), just to name a few. Much of these studies focus on returns correlations, rather than prices (which are intrinsically nonstationary, unlike returns). The main strength of our approach is that it simultaneously accounts for long run comovements amongst stock price indices, whilst endogenously allowing for well-documented shifts in the linkages among financial markets. Indeed, by modelling the long run relationship in prices of different markets, we are able to capture underlying economic fundamentals, otherwise omitted in papers focusing on returns correlation, therefore addressing an important source of misspecification typical of studies of contagion, as pointed out by Favero and Giavazzi (2002) and Forbes and Rigobon (2002). In turn, modelling comovements between different indices may be potentially very useful in improving empirical models of stock returns. ${ }^{3}$

To illustrate our point, we use weekly data from March 1980 to March 2012 for a representative set of markets: the US, the UK and Hong-Kong. Our approach allows us to analyse different episodes in which there may have been changes in financial linkages, in particular covering the recent financial crisis, while incorporating long-term information in

\footnotetext{
${ }^{2}$ Naturally, this also implies a relatively high degree of returns predictability.

${ }^{3}$ Our approach does not focus on the transmission of (measures of) volatility (see King and Wadhwani, 1990, King, Sentana and Wadhwani, 1994 or, more recently, Corradi, Distaso and Fernandes, 2012, amongst others), although it easily allows for heteroskedasticity.
} 
a flexible way. Indeed, we find evidence of momentarily interrupted equilibrium between May 1997 and April 2002, which is consistent with the decoupling of stock prices from fundamentals during the dot-com bubble.

The remainder of the paper is structured as follows. In Section 2 we present the model specification and the data properties, and we discuss the estimation and testing procedures. In Section 3 we illustrate the merits of our approach with an application to USA, UK and Hong Kong financial data and Section 4 concludes.

\section{Cointegration 'Interruptions' in a Single Equation Model}

\subsection{Setup}

In this study, we investigate the linkages amongst a representative group of stock price levels in a cointegration setting. While individual stock prices are integrated processes with infinite unconditional variance (and therefore unpredictable in univariate terms), when prices are cointegrated and the difference between them is mean reverting then we do have information about long run equilibrium, which could be very helpful for policy makers, investor and market participants. The crucial difference is that we allow for potential 'interruption' in the long run equilibria.

Indeed, changes in taste, technology, or economic policies shocks can lead to cases in which cointegration does not hold for some periods of the sample. ${ }^{4}$ The existing literature on cointegration and 'structural' breaks has essentially focused on developing procedures to detect breaks or to estimate the temporal location of eventual parameter shifts (see, for example, Hansen, 1992a, Quintos, 1997, Seo, 1998, Hansen and Johansen, 1999 and Lutkepohl, Saikkonen, and Trenkler, 2003). Nevertheless, a few modelling devices that take into account temporary or permanent, smooth or dramatic shifts in economic cointegrated relationships have also been considered: 'threshold' cointegration as in Blake and Fomby (1997), where the equilibrium error follows a threshold autoregression that is meanreverting outside a given range and has a unit root inside the range; 'Markov-switching' cointegration as in Hall, Psaradakis, and Sola (1997) where the long-run vector switches across states according to a Markov law; 'sudden-shift' cointegration of Hansen (2003), where the coefficient regime shifts are sudden, with a known number of breakpoints; and 'smooth' cointegration by Park and Hahn (1999), Saikkonen and Choi (2004) and Bierens and Martins (2010), where the cointegrating vectors smoothly or gradually change regimes or time.

Modeling nonstationary cointegrated variables with globally stationary equilibrium errors, but locally nonstationary, has not been fully explored in the literature. The notable exceptions are Siklos and Granger (1997), Granger and Yoon (2002) and Kim (2001 and

\footnotetext{
${ }^{4}$ Robert Engle, in his interview for Econometric Theory (volume 19, pages 1175/6) explains that "you may have cointegration for a while, but then you will get big shocks to the system, and those will be permanent shocks, and they will move the cointegrating relationship to a new place. And so you no longer get the reversion to the old equilibrium."
} 
2003). Siklos and Granger call this type of relationships 'regime-sensitive' cointegration and model it through the existence (or not) of an extra common stochastic trend depending on the nature of the policy regime in place. On the other hand, Granger and Yoon (2002) propose 'hidden' cointegration, in which the modelling strategy is based on the decomposition of the time series as cumulative sums of positive and negative shocks. Finally, in Kim's 'segmented' cointegration the equilibrium errors are stationary over time, except for a unique sub-period. He proposes modified ADF and Phillips-Perron $Z_{\alpha}$ and $Z_{t}$ test statistics for cointegration in an $\mathrm{AR}(1)$ model for the disturbance process that is $I(1)$ over the whole sample under the null hypothesis and at a particular subperiod under the alternative.

We pursue an alternative, flexible approach, along the lines of Psaradakis, Sola and Spagnolo (2004). Let $Y_{t}=\left(y_{t}, X_{t}^{\prime}\right)^{\prime}$ with $Y_{t} \in \Re^{k}, y_{t} \in \Re$ and $X_{t} \in \Re^{k-1}$. In its triangular representation, the model is defined as

$$
y_{t}=\mu_{t}+\beta^{\prime} X_{t}+u_{t}
$$

where $\mu_{t}$ contains deterministic components such as an intercept, trend or time-dummies, $\beta$ is a $(k-1) \times 1$ vector of coefficients, $X_{t}=X_{t-1}+v_{t}$, where $v_{t}$ is a stationary zero-mean process that satisfies some functional central limit theorem, and

$$
u_{t}=\rho_{s t} u_{t-1}+\sigma_{s_{t}} \varepsilon_{t}
$$

where $\left\{s_{t}\right\}$ follows a stationary first-order Markov chain in $\{0,1\}$, with transition matrix $P=\left(p_{i j}\right)$, where

$$
p_{i j}=P\left(s_{t}=j \mid s_{t-1}=i\right), i, j \in\{0,1\},
$$

and $\varepsilon_{t}$ follows an i.i.d. $(0,1)$ Gaussian distribution. It is assumed that $\left\{s_{t}\right\}$ is independent of $\left\{\varepsilon_{t}\right\}$. The autoregression and variance parameters, $\rho$ and $\sigma^{2}$, switch between states according to the unobserved Markov chain $\left\{s_{t}\right\}$. In order for momentarily interruptions in the cointegration relationship to exist, there are no absorbing states in the stationary and nonstationary parameter ranges $\left|\rho_{0}\right|<1$ and $\rho_{1}=1: p_{i i} \in(0,1), i=1,2$.

Rearranging terms we obtain the corresponding error-correction model

$$
\triangle y_{t}=\mu_{\triangle t}+\alpha_{s_{t}}\left(\begin{array}{c}
y_{t-1}-\mu_{t-1}-\beta^{\prime} X_{t-1} \\
=u_{t-1}
\end{array}\right)+\eta^{\prime} \triangle X_{t}+\sigma_{s_{t}} \varepsilon_{t},
$$

where $\alpha_{s_{t}}=\rho_{s_{t}}-1, \mu_{\triangle t}=\mu_{t}-\mu_{t-1}$ and $\eta=\beta$. Here, the standard cointegration regime $\alpha_{0}<0$ is interrupted in periods for which no error correction exists $\alpha_{1}=0$.

\subsection{Properties of the Data}

Following the results by Francq and Zakoïan (2001), the "equilibrium" error $u_{t}$ can be characterized as a strictly and second-order (globally) stationary Markov-switching AR 
process, which do not require the usual local stationarity conditions (these are given by $\left|\rho_{i}\right|<1, i=0,1$, for the second-order case). ${ }^{5}$ Define the $2 \times 1$ vector of ergodic probabilities $\xi$, that satisfy the condition $P \xi=\xi$, as $\xi_{i}=P\left(s_{t}=i\right), i \in\{0,1\}$, the unconditional probability that $s_{t}$ will be in regime $i$ at any given date. The sufficient conditions for the existence of a strictly and second-order stationary solutions of (2) are

$$
\begin{gathered}
\xi_{0} \log \left|\rho_{0}\right|+\xi_{1} \log \left|\rho_{1}\right|<0 \text { and } \\
\left(p_{00}+p_{10}\right) \rho_{0}^{2}+\left(p_{01}+p_{11}\right) \rho_{1}^{2}<1,
\end{gathered}
$$

respectively. Moreover, and under the assumption of second-order stationarity and $\left|\rho_{i}\right|<$ $1, i=0,1$, the autocovariance function of $\left\{u_{t}\right\}$ is defined as

$$
E\left(u_{t} u_{t-h}\right)=\iota^{\prime} Q^{h} V
$$

where $\iota=(1,1)^{\prime}, Q=\left(\begin{array}{cc}p_{00} \rho_{0} & p_{10} \rho_{0} \\ p_{01} \rho_{1} & p_{11} \rho_{1}\end{array}\right)$ and $V=\left(\xi_{0} \frac{\sigma_{0}^{2}}{1-\rho_{0}^{2}}, \xi_{1} \frac{\sigma_{1}^{2}}{1-\rho_{1}^{2}}\right)^{\prime}$. In our linear model, with $\left\{u_{t}\right\}$ stationary and $\left\{X_{t}\right\}$ nonstationary, $\left\{y_{t}\right\}$ is nonstationary.

We defined interrupted cointegration for $\left|\rho_{0}\right|<1$ and $\rho_{1}=1$. In this case, it is clear that $\left\{u_{t}\right\}$ is strictly stationary but finite moments will only exist (to obtain second-order stationarity) for

$$
\rho_{0}^{2}<\frac{\left(p_{00}-p_{11}\right)}{\left(p_{00}-p_{11}+1\right)}=1-\frac{1}{\left(p_{00}-p_{11}+1\right)} \text { with } p_{00} \geq p_{11}
$$

That is to say that, in the weak sense, interrupted cointegration needs a "dominant" local stationary state, $s_{t}=0$, that globally offsets the local nonstationarity of the equilibrium term. In Figure 1 we present a simulated interrupted cointegration process generated by (1) and (2) with $k=2, \mu_{t}=0, \beta=1, \rho_{0}=0, \sigma_{s_{t}}=\sigma=1, p_{00}=0.99, p_{11}=0.95$ and $T=500$. The long-term relationship resembles a standard specification one with the exception of a couple of local bubbles (beginning and between observations 200 and 250) that makes the equilibrium go off temporarily. Estimation and inference in this setup is described in more detail in Appendix A.

\section{$<$ Figure 1 here $>$}

\section{Comovements in the US, UK and Hong-Kong equity mar- kets}

In this Section, we apply our proposed model specification and inference to model financial linkages and long run comovements in distinct world financial markets. Several early papers have examined time-varying correlations and volatility transmission. King et al.

\footnotetext{
${ }^{5}$ In fact, local stationarity does not imply global stationarity (Francq and Zakoïan, 2001, page 353).
} 
(1994) studied them for sixteen national stock markets and concluded that changes in correlations across markets are driven primarily by unobservable variables. According to these authors, these can either be omitted variables or investor psychology. Ramchand and Susmel (1998) report that the correlations between the US and other markets are substantially higher when the US market displays high volatility. Caporale et al. (2005) define a significant increase in stock returns co-movement as contagion and find evidence for it in East Asia.

Recent literature has noted that correlations amongst different asset markets has increased since the late 1990s, a situation that could be due to deep "structural" changes such as a reduction in home-bias or the exposure of more internationalised firms to global business cycles, or simply temporary phenomena associated with stock market bubbles and subsequent crashes. A flexible long run approach like ours may help to shed light on this claim.

We focus on three markets, USA, UK and Hong-Kong ( $k=3$, the S\&P 500, the FTSE100 and Hang-Seng indices, respectively) using weekly data taken from Datastream, from March 18, 1980 to March 13, 2012. Our choice of indices is convenient in that it allows us to illustrate the usefulness of our approach in a simple and representative way, while ensuring relevant geographical and economic diversity. We consider the S\&P 500 index as it is largely perceived to be a major forerunner of the US economy, while the main European financial hub is represented by the UK stock market. On the other hand, Honk Kong's Hang Seng well-established index is the second largest in Asia, allowing us to capture Asia specific shocks, as well as the emergence of China as a major player in the world economy (the majority of listed companies are now from mainland China) within the sample period considered in our analysis. ${ }^{6}$

Other choices would have been possible, but each of these indices, and this sample period, are used frequently in this literature. It allow us to capture shocks originating from different markets across the globe, namely the October 1987 crash, the Asian financial crisis in 1997, the 'dot-com' bubble (and subsequent burst) period and the most recent financial crisis, among other episodes. While there is some evidence of increased integration between USA and UK markets (see Kasa, 1992 and Corradi et al. 2012), there is little empirical support for pronounced linkages between Hong-Kong and other markets (see Corhay et al., 1993 and Phylaktis and Ravazzolo, 2005, for example). See Figure 2.

$$
<\text { Figure } 2 \text { here }>
$$

\subsection{Preliminary Analysis}

Before applying our methodology, we perform some of the established cointegration procedures to the above mentioned financial data. We incorporate an intercept in the level equilibrium equation (1), $y_{t}=\mu_{t}+\beta^{\prime} X_{t}+u_{t}$, such that $\mu_{t}=\mu$ and $Y_{t}=\left(y_{t}, X_{t}^{\prime}\right)^{\prime} \in \Re^{3}$, and

\footnotetext{
${ }^{6}$ The Shangai and Shenzen Stock Exchanges are relatively younger indices, and therefore slightly noisier, and have only been in operation since the end of 1990 .
} 
taking as dependent variable $y_{t}$ either one of the three markets of interest. The statistical significance of the constant term is confirmed by the Johansen's (1995) methodology. In fact, the results from this approach suggest that there is lack of evidence for cointegration, as the Trace and Lambda-max test statistics (supported by the Bayesian and Akaike information criteria) found no cointegrating relationships. Moreover, the selected errorcorrection model included only one lag and no deterministic terms in it. We will take all this into account when estimating and testing for interrupted cointegration (see below for details).

To further test the hypothesis of $Y_{t}$ being cointegrated (i.e. if $\left\{u_{t}\right\}$ is $I(0)$ ), we also employ "standard" tests with the null hypothesis of no cointegration (ADF, $Z_{\alpha}$ and $Z_{t}$ tests) ${ }^{7}$, as well as their counterparts that allow for regime shifts, developed by Gregory and Hansen (1996), in which the cointegrating vector may be subject to a regime shift at an unknown time under the alternative hypothesis. ${ }^{8}$ In this framework, since the change point or its occurrence are unknown, the testing procedures involve computing the usual statistics $\left(G H-A E G, G H-Z_{t}\right.$ and $\left.G H-Z_{\alpha}\right)$ for all possible break points and then selecting the smallest value obtained, since it will potentially present greater evidence against the null hypothesis of no cointegration.

The tests described above are based on the principle of testing for a unit root in the residuals of the cointegrating regression. Other tests have been developed which test whether the residuals are stationary and, therefore, have cointegration as the null hypothesis. Since we are focusing on the effects of neglected parameter changes, it is also interesting to relate cointegration tests with structural change tests, as the former may be derived from the latter. Hansen (1992a) proposed some LM-type structural change tests in cointegrated models, making use of the fully-modified OLS (FM-OLS) estimator. Shin (1994) and McCabe et al. (1997), for example, extend its use to test for the null hypothesis of cointegration. Here, we use the latter version (the $M L S$ statistic) based on the dynamic OLS estimator of Saikkonen (1991) with filtered residuals from an $\operatorname{ARIMA}(p, 1,1)$ model and the variance estimator $\left(\hat{\sigma}^{2}\right)$ proposed in Leybourne and McCabe (1999); see McCabe et al. (1997) for more details on the computation of the statistic.

It is important, however, to stress that a researcher should be cautious in interpreting the results of these tests. For instance, the $M L S$ statistic also has power against parameter instability. The only plausible conclusion one can draw from a rejection is that the traditional specification of a cointegration model such as (1) (assuming parameter stability) is not supported by the data. The same applies to structural change tests used as cointegration tests.

\footnotetext{
${ }^{7}$ To choose an appropriate lag length for the ADF test, we adopt a downward testing selection procedure based on two-sided $5 \%$-level $t$-type tests for the significance of the coefficient on the longest lag, with the maximum lag length set equal to 8. For the $Z_{\alpha}$ and $Z_{t}$ tests, the long-run variance of $\left\{\eta_{t}\right\}$ is estimated by using a prewhitened quadratic spectral kernel estimator with a data-based bandwidth and a first-order autoregressive prewhitening filter, as recommended in Andrews and Monahan (1992).

${ }^{8}$ Gregory and Hansen (1996) analyzed models that accommodate under the alternative hypothesis of cointegration the possibility of changes in parameters, namely an intercept shift model $(C)$, as well as a "regime shift" model $(C / S)$ where both the constant and slope parameters change, see paper for details.
} 
Finally, we employ the rank tests devised by Qu (2007) and the segmented cointegration tests proposed by Kim (2003). The former are multivariate versions of the variance-ratio statistic whose ordered eigenvalues carry information about the cointegration rank. ${ }^{9}$ The null hypothesis in Qu's tests is no cointegration $\left(r_{0}=0\right)$ and the SQ and WQ test statistics are performed at a $5 \%$ level. Kim's test statistics are modified versions of the original tests for standard cointegration such that, under the alternative, they allow for the existence of a unique subperiod $\left(\mathrm{N}_{T}\right)$ where the errors of the model are nonstationary (we label those tests $\mathrm{ADF}_{-} s c, Z_{\alpha_{-}} s c$ and $Z_{t_{-}} s c$ ). The tests were computed for a maximum number of $\lfloor 0.3 T\rfloor$ observations for the single no cointegration period, in order to use the available critical values in the paper. The results obtained for the standard tests for cointegration, including Qu's and Kim's approaches, are presented in Table 1.

$<$ Table 1 here $>$

Almost all tests for the null hypothesis of no cointegration fail to reject (thus indicating that the markets are not integrated) whereas the KPSS-type test (MLS) of McCabe et al. (1997) rejects the existence of a (stable) long-run relationship between the series, except for the Hong Kong regression. Nevertheless, the tests $G H-Z_{\alpha}$ and $G H-Z_{t}$ of Gregory and Hansen (1996) provide some evidence for cointegration subject to a regime shift, with the exception of Hong Kong. Resorting to the tests of $\mathrm{Qu}$ (2007), where all variables are endogenous, it does not save the day either since these tests also fail to indicate the presence of cointegration, even if interrupted. We also have mixed results with respect to the tests of Kim (2003). The ADF statistic finds no cointegration over the whole period, except for the UK, whereas according to the $Z_{\alpha}$ and $Z_{t}$ statistics there is segmented cointegration (the estimated no cointegration periods are referred as $\mathrm{N}_{T}$ ).

Hence, a researcher using these tools would find mixed results in support for the existence of a common, unifying trend in international finance markets, a result consistent with many papers in the literature. However, recalling that Qu's tests exhibit low power against our model specification (1) and (2), Kim's and Gregory and Hansen's $Z_{\alpha}$ and $Z_{t}$ statistics raise the possibility of long-run equilibrium relationships that are momentarily interrupted, to which we turn next.

\section{2 'Interrupted' cointegration}

Now, consider the analysis of our data in terms of the model specification of Section 2, that accounts for the existence of short-period interruptions of the cointegration relationship. After obtaining the least squares residuals $\widehat{u}_{t}$, we estimate the model $\widehat{u}_{t}=\rho_{s_{t}} \widehat{u}_{t-1}+\sigma_{s_{t}} \varepsilon_{t}$ by ML assuming that the unobserved process $\left\{s_{t}\right\}$ follows a stationary first-order Markov

\footnotetext{
${ }^{9}$ They include the supQm1, supQm2 and supQm3 statistics for which it is known the number of changes under the alternative (one up to three, in this case), the WQ and SQ statistics when the number of shifts is unknown, and the SupQF, SupQR and SupQW statistics when some prior information about the timing of the change is known up front (the higher cointegration rank occurs at the beginning, the end or middle of the sample, respectively).
} 
chain in $\{0,1\}$, with transition matrix $P=\left(p_{i j}\right)$, and $\varepsilon_{t}$ follows an i.i.d.(0,1) Gaussian distribution. To provide more information to the analysis, we also estimate the model $\triangle y_{t}=\alpha_{s_{t}} \widehat{u}_{t-1}+\eta^{\prime} \triangle X_{t}+\sigma_{s_{t}} \varepsilon_{t}$, with an error-correction term whose coefficient is driven by the Markovian law $\left\{s_{t}\right\}$. The estimation results for $\rho_{0}, \rho_{1}, \sigma_{0}, \sigma_{1}, p_{00}, p_{11}$ and $\alpha_{0}, \alpha_{1}$ and the testing result for a null of $\rho_{1}=1$, as well as the estimation and testing for the linear model (no parameter switches) and the calculation of information criteria, are reported in Table 2 .

$<$ Table 2 here $>$

According to the results above, the Markov-switching specification delivers incremental explanatory power over the linear model. Testing the null of parameter stability using Hansen's (1992b) likelihood ratio test for a null of a single regime gives a p-value of zero and all the information criteria favours a Markov switching model (reported as the difference between criteria for the MS and linear specifications in Table 2).

In all three cases there is a change in the amount of variance of the error term, as we observe a larger variance in state 0 . On the other hand, Markov switching in the autoregressive coefficient is not statistically significant only in the case of Hong Kong. For the other two, one finds evidence of a rejection of the hypothesis of parameter constancy with a smaller autoregressive coefficient in state 0 .

This means that, with the exception of Hong Kong, there seems to exist a stochastic shift in the memory of the (potentially equilibrium) error which may be capturing shifts from stationarity/non-stationarity as long as $\rho_{1}=1$. In fact, the results lead us to conclude in favor of this last statement because the two p-values of the test $\rho_{1}=1$ are greater than $10 \%$. That is to say, there is evidence of interrupted cointegration for the USA and UK cases. On the contrary, the HK case only presents a shift in the variance and, at a $5 \%$ level, we conclude that there is cointegration for the whole time span. Note that $\rho_{0}=\rho_{1}$ cannot be rejected and the p-value of the test $\rho_{1}=1$ equals 0.038 .

When we model interrupted cointegration by means of the error-correction specification, we confirm the empirical support found earlier for the USA and UK economies. The results in the bottom panel of Table 2 show that $\alpha_{0}-\alpha_{1}$ is statistically significant with a non-rejection of $\alpha_{1}=0$ and a negative value for the point estimation of $\alpha_{0}-\alpha_{1}$. For the HK case, the null $\alpha_{0}=\alpha_{1}$ cannot be rejected and the same applies to $\alpha_{1}<0$, meaning that cointegration does not appear to be interrupted. In sum, the HK is the only case where the definition of interrupted cointegration does not seem to apply. We should also stress that the magnitude of the $\alpha$ 's (close to zero, albeit significant) indicates that any deviations from the long run equilibrium take a long time to be restored. This may help to explain why some studies fail to find the presence of cointegration.

Finally, we date regime 1 (momentarily interrupted cointegration) for the USA and the UK economies and compare it to the results obtained using Kim's segmented cointegration approach (see $\mathrm{N}_{T}$ in Table 1 above). In Figures 3 and 4 we have the estimated residuals obtained from model (1) (top) and the estimated filtered probabilities associated with the 
local cointegration regime (state 0 , bottom) for the USA and UK, respectively. For a matter of comparison, we also present in Figure 5 the estimated probabilities of state 0 but now for the error correction model (USA on the top and UK on the bottom).

$<$ Figures 3 and 4 and 5 here $>$

As expected, due to the estimated values for $p_{i i}$ of around 0.98 , the number of periods staying in each regime is relatively large, especially until 1997. Broadly speaking, until 1997 there was cointegration for most of the time and since then there is lack of evidence for cointegration of the financial indices. In particular, before 1997 there was interrupted cointegration in 1987 and, after 1997 there was cointegration momentarily in 2002, 2004, 2005, 2006 and then in 2010. Remarkably, this contrasts to Kim's dating where cointegration exists only after mid 1987, maybe due to the fact that in Kim's method there is only one single period of no cointegration.

These findings are remarkable, and in some ways run counter intuition, in that they reveal that, despite evidence of low correlations across national stock markets, cointegration has indeed been present for the first part of the sample, until the mid-1990's. Long term gains from international diversification were limited, though it is interesting to note that temporary "interruptions" in this first period are associated with periods of high stock market volatility, such as the 1987 crash or the first Gulf War. Towards the end of the 1990's, coinciding with the notion of increased integration, we have in fact periods where cointegration is largely absent. This coincided with the run-up of the 'dotcom' bubble and subsequent burst, the South East Asia crisis and, more recently, with the financial crisis initiated in 2007. Short bursts of temporary cointegration occur sporadically, but the period is largely dominated by the lack of a strong unifying market force, which has given rise to the opportunities for international portfolio diversification. Note also that this is consistent with the "irrational exuberance" argument, in which prices are "detached" from fundamentals. What is interesting in our analysis is that we seem to find evidence that this decoupling in the co-movement of the markets appears to somehow be associated with periods of market volatility, something that has been hitherto unexplored.

\section{Conclusion}

The long standing perception fact that national stock markets display low correlations is being increasingly challenged. Indeed, the recent financial crisis has highlighted how difficulties originating in a well circumscribed setting (defaults in the US sub-prime market) have led to dramatic and unforeseen consequences across financial markets and different economies. In this study, we proposed the use of an 'interrupted' Markov switching cointegration specification to study the time-varying nature of long run comovements across national equity markets. While there may be underlying factors that can explain long term changes in correlations across markets (such as increased flows of capital across countries, 
market deregulation, improvements in communications and trading systems or the appearance of new financial products), there might be other forces that destabilise linkages across markets.

Using an illustrative sample of selected equity markets (USA, UK and Hong Kong), with data from 1989 to 2012, we find evidence of interrupted cointegration across these markets between May 1997 and April 2002, which is consistent with the decoupling of stock prices from fundamentals during the dot-com bubble. Such discontinuities in crosscountry linkages are a concern for both investors and policymakers. On the one hand, these shifts imply that the composition of long run 'optimal' portfolios is subject to significant changes. Moreover, if asset markets are unusually synchronised during highly volatile periods, this leads to restricted opportunities for diversification of international portfolios, just when the benefits of risk spreading are most needed. This, however, is mitigated by the fact that, as our results suggest, this is subsequently followed by periods where long run market linkages are 'interrupted'.

On the other hand, 'abnormal' comovement in international equity prices implies that shocks in one country are more likely to be transmitted to other markets, even when these have better fundamentals, therefore endangering global financial stability. This has consequences for the design of stabilization policies, but also for regulation and supervision of national financial systems. These spillovers can be further amplified to the real economy through the usual channels, but also because of greater share holdings by households. Crucially, however, is the view supported by our results that these shifts signal different regimes in the international transmission of financial shocks, which suggests that policymakers need to carefully monitor changes in international comovements using flexible modelling tools. In the absence of internationally coordinated policy responses, the changing nature of market comovements may justify some short-term measures (such as controls on capital flows or temporary easing/tightening of monetary policy) employed at the national level to stymie cross-country transmission of shocks. However, the statecontingent nature of these short-run isolation strategies could lead to increased "policy uncertainty', thus increasing the cost of these policies.

The lack of consensus about the appropriate policy responses in this context requires more careful modelling, both theoretical and empirical. Our approach does not allow us to provide a structural explanation for the links between (interrupted) cointegration and periods of market turmoil, but it is useful in uncovering the time-varying nature of international financial linkages. Admitting that 'interrupted' cointegration may exist in other kinds of economic and financial data, it would be interesting to apply this methodology to distinct models. Lastly, extending this approach to the multivariate setup is a worthwhile exercise that is currently being undertaken by the authors.

Acknowledgements: Financial support under grant PTDC/EGE-ECO/122093/2010 from the Fundação para a Ciência e Tecnologia is gratefully acknowledged. We thank two anonymous referees, Valentina Corradi, Marcelo Fernandes, Apostolos Thomadakis, as well 
as participants at the Fall Meeting of the Econometric Time Series European Research Network and the $11^{\text {th }}$ INFINITI Conference in Aix-en-Provence for helpful comments and suggestions.

\section{References}

[1] Acharya, V. and Pedersen, L. (2005), "Asset pricing with liquidity risk", Journal of Financial Economics, 77, 375-410.

[2] Aggarwal, R., Lucey, B. M. and Muckley, C (2004) "Dynamics of Equity Market Integration in Europe: Evidence of Changes over time and with events," The Institute for International Integration Studies Discussion Paper Series, No. 19.

[3] Allen, F. and Gale, D. (2000), "Financial contagion", Journal of Political Economy, $108,1-33$.

[4] Andrews, D. W. K. and Monahan, J. C. (1992), "An improved heteroskedasticity and autocorrelation consistent covariance matrix estimator," Econometrica, 60, 953-966.

[5] Arshanapalli, B. and Doukas, J. (1993), "International stock market linkages: Evidence from the pre- and post- October 1987 period", Journal of Banking and Finance, 17, 193-208.

[6] Bekaert, G. and Harvey, C. R. (1995), "Time-varying world market integration", Journal of Finance, 50, 403-444.

[7] Bierens, H. and Martins, L.F. (2010), "Time Varying Cointegration," Econometric Theory, 26, 1453-1490.

[8] Blake, N. S. and Fomby, T. B. (1997), "Threshold Cointegration," International Economic Review, 38, 627-645.

[9] Brunnermeier, M. and Pedersen, L. (2009), "Market liquidity and funding liquidity", Review of Financial Studies, 22, 2201-2238.

[10] Campbell, J. (1987), "Stock returns and the term structure", Journal of Financial Economics, 18, 373-400.

[11] Caporale, G. M., Cipollini, A., and Spagnolo, N. (2005). Testing for Contagion: A Conditional Correlation Analysis, Journal of Empirical Finance, 12, 627-645.

[12] Chou, R. Y., Ng, V. and Pi, L. K. (1994), "Cointegration of International Stock Market Indices", IMF Working Papers 94/94, International Monetary Fund.

[13] Corhay, A. A., Rad, T. and Urbain, J. (1993), "Common stochastic trends in European stock markets", Economics Letters, 42, 385-390. 
[14] Corradi, V., Distaso, W. and Fernandes, M. (2012), "International market links and volatility transmission", Journal of Econometrics, 170, 117-141.

[15] Favero, C. A. and Giavazzi, F. (2002), "Is the international propagation of financial shocks non-linear?: Evidence from the ERM," Journal of International Economics, $57,231-246$

[16] Forbes, K. J. and Rigobon, R. (2001), "Measuring contagion: conceptual and empirical issues", in S. Claessens and K. J. Forbes (eds.), International Financial Contagion (pp. 43-66), Kluwer.

[17] Forbes, K. J. and Rigobon, R. (2002), "No contagion, only interdependence: measuring stock markets comovements, Journal of Finance, 57, 2223-2261.

[18] Francq, C. and Zakoïan, J.-M. (2001), "Stationarity of multivariate Markov-switching ARMA models," Journal of Econometrics 102, 339-364.

[19] Garcia, R. and Tsafack, G. (2011), "Dependence structure and extreme comovements in international equity and bond markets," Journal of Banking and Finance, 35, 1954-1970.

[20] Granger, W. J. C. and Yoon, G. (2002), "Hidden Cointegration," Working Paper, Department of Economics, UCSD.

[21] Gregory, A. W. and Hansen, B. E. (1996), "Residual-based tests for cointegration in models with regime shifts," Journal of Econometrics, 70, 99-126.

[22] Haldane, A.G. and Hall, S.G. (1991), "SterlingÕs relationship with the Dollar and the Deutschemark: 1976-89", Economic Journal, 101, 436-443.

[23] Hall, S. G., Psaradakis, Z., and Sola, M. (1997), "Cointegration and Changes in Regime: the Japanese Consumption Function," Journal of Applied Econometrics 12, 151-168.

[24] Hamilton, J. D. (1989), " A New Approach to the Economic Analysis of Nonstationary Time Series and the Business Cycle," Econometrica, 57, 357-384.

[25] Hamilton, J. D. (1994), "Time Series Analysis," Princeton University Press, Princeton.

[26] Hansen, B. E. (1992a), "Tests for Parameter Instability in Regressions with I(1) Processes," Journal of Business and Economic Statistics, 10, 321-335.

[27] Hansen, B. E. (1992b), "The likelihood ratio test under non-standard conditions: Testing the Markov trend model of GNP," Journal of Applied Econometrics, 7, 6182. 
[28] Hansen, P. R. (2003), "Structural Changes in the Cointegrated Vector Autoregressive Model," Journal of Econometrics, 114, 261-295.

[29] Hansen, H. and Johansen, S. (1999), "Some Tests for Parameter Constancy in Cointegrated VAR-models," Econometrics Journal 2, 306-333.

[30] Johansen, S. (1995), "Likelihood Based Inference in Cointegrated Vector Autoregressive Models," Oxford University Press, Oxford.

[31] Kasa, K. (1992), "Common stochastic trends in international stock markets", Journal of Monetary Economics. 29, 95-124.

[32] Kim, J.Y. (2001), "Inference on Segmented Cointegration and Reconsideration of the Fisher Relation," Discussion paper, Department of Economics, State University of New York at Albany.

[33] Kim, J.-Y. (2003), "Inference on Segmented Cointegration," Econometric Theory 19, 620-639.

[34] Kim, C.-J. and Nelson, C. R. (1999), "State-space Models with Regime Switching," MIT Press, Cambridge.

[35] King, M. and Wadhwani, S. (1990), "Transmission of volatility between stock markets", Review of Financial Markets, 3, 5-33.

[36] King, M., Sentana, E., and Wadhwani, S. (1994). Volatility and Links between National Stock Markets. Econometrica, 4, 901-933.

[37] Kiyotaki, N. and Moore, J. (2002), "Evil is the root of all money", American Economic Review: Papers and Proceedings, 92, 62-66.

[38] Kodres, L. and Pritsker, M. (2002), "A rational expectations model of financial contagion", Journal of Finance, 57, 769-800.

[39] Leybourne, S. J. and McCabe, B. P. M. (1999), "Modified stationarity tests with data-dependent model-selection rules," Journal of Business and Economic Statistics, $17,264-270$.

[40] Longin, F. M. and Solnik, B. (1995), "Is the correlation in international equity returns constant?: 1960-1990", Journal of International Money and Finance, 14, 3-26.

[41] Lutkepohl, H., Saikkonen, P. and Trenkler, C. (2003), "Comparison of Tests for the Cointegrating Rank of a VAR Process with a Structural Shift," Journal of Econometrics 113, 201-229.

[42] Manning, N. (2002), "Common trends and convergence? South East Asian equity markets, 1988-1999", Journal of International Money and Finance, 21, 183-202. 
[43] McCabe, B. P. M. and Leybourne, S. J. and Shin, Y. (1997), "A parametric approach to testing for the null of cointegration," Journal of Time Series Analysis, 18, 395-413.

[44] Park, J. Y. and Hahn, S. B. (1999), "Cointegrating Regressions with Time Varying Coefficients," Econometric Theory 15, 664-703.

[45] Phylaktis, K. and Ravazzolo, F. (2005), "Stock market linkages in emerging markets: implications for international portfolio diversification", Journal of International Financial Markets, Institutions and Money, 15, 91-106.

[46] Psaradakis, Z., Sola, M. and Spagnolo, F. (2004), "On Markov error-correction models, with an application to stock prices and dividends", Journal of Applied Econometrics, 19, 69-88.

[47] Qu, Z. (2007), "Searching for cointegration in a dynamic system," Econometrics Journal, 10, 580-604.

[48] Quintos, C. E. (1997), "Stability Tests in Error Correction Models," Journal of Econometrics 82, 289-315.

[49] Ramchand, L. and Susmel, R. (1998), Volatility and Cross Correlation Across Major Stock Markets, Journal of Empirical Finance, 5, 397-416.

[50] Richards, A. J. (1995), "Comovements in national stock market returns: Evidence of predictability, but not cointegration", Journal of Monetary Economics, 36, 631-654.

[51] Rodriguez, J. C. (2007), "Measuring financial contagion: a copula approach", Journal of Empirical Finance, 14, 401-423.

[52] Saikkonen, P. (1991), "Asymptotically efficient estimation of cointegrating regressions," Econometric Theory, 7, 1-21.

[53] Saikkonen, P. and Choi, I. (2004), "Cointegrating Smooth Transition Regressions," Econometric Theory 20, 301-340.

[54] Seo, B. (1998), "Tests for Structural Change in Cointegrated Systems," Econometric Theory 14, 222-259.

[55] Shin, Y. (1994), "A residual-based test of the null of cointegration against the alternative of no cointegration," Econometric Theory, 10, 91-115.

[56] Siklos, P. L. and Granger, C.W.J. (1997), "Regime-Sensitive Cointegration With An Application To Interest-Rate Parity," Macroeconomic Dynamics, vol. 1(3), 640-657.

[57] Stock, J. H. (1987), "Asymptotic Properties of Least Squares Estimation of Cointegrating Vectors," Econometrica, 55, 153-174. 
[58] Umutlu, M., Akdeniz, L. and Altag-Salih, A. (2010), "The degree of financial liberalization and aggregated stock-return volatility in emerging markets", Journal of Banking and Finance, 34, 485-696.

\section{Appendix A: Estimation and Inference}

The estimation of models (1) and (2) can be pursued in a straightforward manner in a two-stage procedure. In the first step, estimate $\left(\mu_{t}, \beta\right)$ by least squares and obtain the residuals $\widehat{u}_{t}$. As shown by Stock (1987), this estimator happens to be superconsistent. In the second step, use maximum likelihood estimation, through numerical optimization or with an EM algorithm, to a two-regime Markov-Switching AR(1) model of the residuals $\widehat{u}_{t}$, along the lines of the procedure suggested in Hamilton (1989) (see also Hamilton, 1994, chapter 22, and Kim and Nelson, 1999, for more details).

The Markov-Switching model is specified as

$$
\widehat{u}_{t}=\rho_{s_{t}} \widehat{u}_{t-1}+\sigma_{s_{t}} \varepsilon_{t},
$$

with the the set of unknown parameters

$$
\theta=\left\{\rho_{0}, \rho_{1}, \sigma_{0}, \sigma_{1}, p_{11}, p_{22}\right\}
$$

Similarly, the Markov-Switching error correction model (4) can be estimated by maximum likelihood as well, with $u_{t-1}$ replaced by first-step residuals $\widehat{u}_{t-1}$.

The estimation and inference of the parameters $\theta$ is carried out by maximizing the likelihood function of the model. It involves recursive computation of probabilities about the unobserved regimes and obtaining $\widehat{\theta}$ that maximizes the log-likelihood function. By normality of the innovations shocks $\varepsilon_{t}, \varepsilon_{t} \sim i . i . d . N[0,1]$, the conditional density of $\widehat{u}_{t}$ on $s_{t}=i \in\{0,1\}$ is

$$
f\left(\widehat{u}_{t} \mid s_{t}=i, \widehat{u}_{t-1} ; \theta\right)=\frac{1}{\sigma_{s_{t}} \sqrt{2 \pi}} \exp \left[-\frac{\left(\widehat{u}_{t}-\rho_{s_{t}} \widehat{u}_{t-1}\right)^{2}}{2 \sigma_{s_{t}}^{2}}\right]
$$

and the unconditional density of $\widehat{u}_{t}$ is

$$
\begin{aligned}
f\left(\widehat{u}_{t} \mid \widehat{u}_{t-1} ; \theta\right) & =f\left(\widehat{u}_{t} \mid s_{t}=0, \widehat{u}_{t-1} ; \theta\right)+f\left(\widehat{u}_{t} \mid s_{t}=1, \widehat{u}_{t-1} ; \theta\right) \\
& =\xi_{0} f\left(\widehat{u}_{t} \mid s_{t}=0, \widehat{u}_{t-1} ; \theta\right)+\xi_{1} f\left(\widehat{u}_{t} \mid s_{t}=1, \widehat{u}_{t-1} ; \theta\right) .
\end{aligned}
$$

Hence, the log-likelihood for the observed data $\left(\widehat{u}_{1}, \ldots, \widehat{u}_{T}\right)$ given $\widehat{u}_{0}$, with $s_{t}$ i.i.d. across 
$t$, is

$$
\begin{aligned}
l(\theta) & =\sum_{t=1}^{T} \log f\left(\widehat{u}_{t} \mid \widehat{u}_{t-1} ; \theta\right)+\log f\left(\widehat{u}_{0} ; \theta\right) \approx \sum_{t=2}^{T} \log f\left(\widehat{u}_{t} \mid \widehat{u}_{t-1} ; \theta\right) \\
& =\sum_{t=2}^{T} \log \left(\frac{\xi_{0}}{\sigma_{0} \sqrt{2 \pi}} \exp \left[-\frac{\left(\widehat{u}_{t}-\rho_{0} \widehat{u}_{t-1}\right)^{2}}{2 \sigma_{0}^{2}}\right]+\frac{\xi_{1}}{\sigma_{1} \sqrt{2 \pi}} \exp \left[-\frac{\left(\widehat{u}_{t}-\rho_{1} \widehat{u}_{t-1}\right)^{2}}{2 \sigma_{1}^{2}}\right]\right)
\end{aligned}
$$

The MLE is obtained by constrained maximization of $l(\theta)$ and the corresponding EM algorithm starts from an arbitrary initial guess for the value of $\theta, \theta^{(0)}=\left\{\rho_{0}, \rho_{1}, \sigma_{0}, \sigma_{1}, \xi_{0}, \xi_{1}\right\}$; afterwards, it calculates $P\left(s_{t}=i \mid \widehat{u}_{t}, \widehat{u}_{t-1} ; \theta\right)$ from

$$
P\left(s_{t}=i \mid \widehat{u}_{t}, \widehat{u}_{t-1} ; \theta\right)=\xi_{i} \frac{f\left(\widehat{u}_{t} \mid s_{t}=i, \widehat{u}_{t-1} ; \theta\right)}{f\left(\widehat{u}_{t} \mid \widehat{u}_{t-1} ; \theta\right)}
$$

defined previously; then, it calculates $\widehat{\xi}_{i}, \widehat{\rho}_{i}$ and $\widehat{\sigma}_{i}, i=0,1$, denoted as $\theta^{(1)}$, using the respective ML numerical formulas; and, it repeats the former two steps until convergence is achieved at the $m^{t h}$ iteration: $\left\|\theta^{(m+1)}-\theta^{(m)}\right\|<\epsilon$, for some arbitrarily small $\epsilon$.

Now, we discuss inference about regimes and how to forecast future interruptions in cointegrated time series. Denoting $\mathbb{U}_{t}=\left(\widehat{u}_{t}, \widehat{u}_{t-1}, \ldots, \widehat{u}_{1}\right)^{\prime}$, the filtered regime probabilities and the optimal forecast about each regime are defined as $\widehat{\vartheta}_{t \mid t}=\left(P\left(s_{t}=0 \mid \mathbb{U}_{t} ; \widehat{\theta}\right), P\left(s_{t}=1 \mid \mathbb{U}_{t} ; \widehat{\theta}\right)\right)^{\prime} \in$ $\Re^{2}$ and $\widehat{\vartheta}_{t+1 \mid t}=\left(P\left(s_{t+1}=0 \mid \mathbb{U}_{t} ; \widehat{\theta}\right), P\left(s_{t+1}=1 \mid \mathbb{U}_{t} ; \widehat{\theta}\right)\right)^{\prime}$, respectively, and obtained by iterating for each $t$

$$
\widehat{\vartheta}_{t \mid t}=\frac{\left(\widehat{\vartheta}_{t \mid t-1} \odot \widehat{\eta}_{t}\right)}{\iota^{\prime}\left(\widehat{\vartheta}_{t \mid t-1} \odot \widehat{\eta}_{t}\right)}=\frac{\left(\widehat{\vartheta}_{t \mid t-1} \odot \widehat{\eta}_{t}\right)}{f\left(\widehat{u}_{t} \mid \widehat{u}_{t-1} ; \widehat{\theta}\right)} \text { and } \widehat{\vartheta}_{t+1 \mid t}=\widehat{P} \widehat{\vartheta}_{t \mid t} \text {, }
$$

where $\iota \in \Re^{2}$ is a vector of ones, $\odot$ denotes element-by-element multiplication and $\widehat{\eta}_{t}=$ $\left(f\left(\widehat{u}_{t} \mid s_{t}=0, \widehat{u}_{t-1} ; \widehat{\theta}\right), f\left(\widehat{u}_{t} \mid s_{t}=1, \widehat{u}_{t-1} ; \widehat{\theta}\right)\right)^{\prime} \in \Re^{2}$. For initialization, use $\widehat{\vartheta}_{1 \mid 0}=\widehat{\xi}$ or $\widehat{\vartheta}_{1 \mid 0}=\frac{1}{2} \iota$. Smoothed inferences, $\widehat{\vartheta}_{t \mid T}=\widehat{\vartheta}_{t \mid t} \odot\left[\widehat{P}^{\prime}\left(\widehat{\vartheta}_{t+1 \mid T} \oslash \widehat{\vartheta}_{t+1 \mid t}\right)\right]$, are obtained doing backward iteration for $t=T-1, T-2, \ldots, 1$, where $\oslash$ denotes element-by-element division. The optimal $m$-period-ahead forecast of $\vartheta_{t+m}$ is given by $\widehat{\vartheta}_{t+m \mid t}=\widehat{P}^{m} \widehat{\vartheta}_{t \mid t}$ and of $\widehat{u}_{t+m}$ is $E\left(\widehat{u}_{t+m} \mid \mathbb{U}_{t} ; \theta\right)=h_{t+m} \widehat{\vartheta}_{t+m \mid t}$, where

$$
h_{t+m}=\left(E\left(\widehat{u}_{t+m} \mid s_{t+m}=0, \mathbb{U}_{t} ; \theta\right), E\left(\widehat{u}_{t+m} \mid s_{t+m}=1, \mathbb{U}_{t} ; \theta\right)\right)=\left(\rho_{0}^{m} \widehat{u}_{t}, \rho_{1}^{m} \widehat{u}_{t}\right) .
$$

The above mentioned concept of interrupted cointegration assumes that $\left|\rho_{0}\right|<1$ and $\rho_{1}=1$. To test the null hypothesis of $H_{0}: \rho_{1}=1$ is a standard exercise. The likelihood ratio statistic

$$
L R_{T}=2\left(l(\widehat{\theta})-l\left(\widehat{\theta}_{R}\right)\right)
$$

is asymptotically $\chi_{(1)}^{2}$-distributed, where $\theta_{R}=\left\{\rho_{0}, 1, \sigma_{0}, \sigma_{1}, p_{11}, p_{22}\right\}$. 


\section{Appendix B: Tables and Figures}

Table 1: Standard Cointegration Analysis

\begin{tabular}{|c|c|c|c|}
\hline & $y$ is the $U S A$ & $y$ is the $U K$ & $y$ is $H K$ \\
\hline $\mathrm{ADF}$ & -2.492 & -2.579 & -3.426 \\
\hline$Z_{\alpha}$ & -17.171 & -18.517 & -19.719 \\
\hline$Z_{t}$ & -2.991 & -3.087 & -3.186 \\
\hline$G H-A D F \quad(C)$ & $-4.819^{*}$ & -4.573 & -4.503 \\
\hline$(C / S)$ & $-5.029^{*}$ & $-5.026^{*}$ & -4.647 \\
\hline$G H-Z_{\alpha}$ & $-48.876^{*}$ & $-45.524^{*}$ & -36.673 \\
\hline$(C / S)$ & $-53.052^{*}$ & $-53.213^{*}$ & $-41.705^{*}$ \\
\hline$G H-Z_{t}$ & $-4.982^{*}$ & $-4.829^{*}$ & -4.303 \\
\hline$(C / S)$ & $-5.201^{*}$ & $-5.266^{*}$ & -4.603 \\
\hline$M L S$ & $1.259^{*}$ & $2.114^{*}$ & 0.074 \\
\hline $\mathrm{ADF}_{-} s c$ & -4.073 & $-4.367^{*}$ & -3.965 \\
\hline $\mathrm{N}_{T}$ & - & $20 / 12 / 88-14 / 04 / 98$ & - \\
\hline $\begin{array}{l}Z_{\alpha_{-}} s c \\
\mathrm{~N}_{T}\end{array}$ & $\begin{array}{c}-5343.169^{*} \\
18 / 03 / 80-21 / 04 / 87\end{array}$ & $\begin{array}{c}-84615.474^{*} \\
18 / 03 / 80-21 / 04 / 87\end{array}$ & $\begin{array}{c}-3411615.284^{*} \\
13 / 01 / 98-14 / 08 / 07\end{array}$ \\
\hline$Z_{t \_} s c$ & $\begin{array}{c}-51.617^{*} \\
18 / 03 / 80-21 / 04 / 87\end{array}$ & $\begin{array}{c}-205.663^{*} \\
18 / 03 / 80-21 / 04 / 87\end{array}$ & $\begin{array}{c}-1306.058^{*} \\
13 / 01 / 98-14 / 08 / 07\end{array}$ \\
\hline \multicolumn{4}{|c|}{$r_{0}=0$} \\
\hline supQm1 & supQm2 & supQm3 & SupQF \\
\hline 2.802 & 7.630 & 9.630 & 2.100 \\
\hline SupQR & SupQW & SQ & WQ \\
\hline 0.709 & 4.258 & 7.853 & 5.050 \\
\hline
\end{tabular}

Notes: * stands for a $5 \%$ significance level. 
Table 2: Interrupted Cointegration in Financial Markets

\begin{tabular}{|c|c|c|c|}
\hline & $y$ is the $U S A$ & $y$ is the $U K$ & $y$ is $H K$ \\
\hline \multicolumn{4}{|l|}{ Linear } \\
\hline$\rho$ & $\begin{array}{l}0.983^{*} \\
(0.004)\end{array}$ & $\begin{array}{l}0.981 * \\
(0.004)\end{array}$ & $\begin{array}{l}0.991 * \\
(0.005)\end{array}$ \\
\hline$\sigma$ & 15.531 & 68.649 & 404.029 \\
\hline p-value $\left(H_{0}\right.$ linear $)$ & 0.000 & 0.000 & 0.000 \\
\hline \multicolumn{4}{|l|}{ MS } \\
\hline$\rho_{1}$ & $\begin{array}{l}0.996^{*} \\
(0.003)\end{array}$ & $\begin{array}{l}0.995^{*} \\
(0.003)\end{array}$ & $\begin{array}{l}0.992^{*} \\
(0.004)\end{array}$ \\
\hline$\rho_{0}-\rho_{1}$ & $\begin{array}{c}-0.039^{*} \\
(0.017)\end{array}$ & $\begin{array}{c}-0.035^{*} \\
(0.014)\end{array}$ & $\begin{array}{c}-0.001 \\
(0.005)\end{array}$ \\
\hline$\sigma_{1}$ & $\begin{array}{l}7.871^{*} \\
(0.708)\end{array}$ & $\begin{array}{l}34.326^{*} \\
(2.326)\end{array}$ & $\begin{array}{l}81.307^{*} \\
(3.192)\end{array}$ \\
\hline$\sigma_{0}-\sigma_{1}$ & $\begin{array}{l}14.790^{*} \\
(1.348)\end{array}$ & $\begin{array}{c}65.008^{*} \\
(5.396)\end{array}$ & $\begin{array}{c}426.193^{*} \\
(17.421)\end{array}$ \\
\hline$p_{00}$ & $\begin{array}{l}0.981 \\
(0.601)\end{array}$ & $\begin{array}{l}0.982 \\
(0.612)\end{array}$ & $\begin{array}{l}0.997 \\
(1.165)\end{array}$ \\
\hline$p_{11}$ & $\begin{array}{l}0.988 \\
(0.480)\end{array}$ & $\begin{array}{l}0.988 \\
(0.527)\end{array}$ & $\begin{array}{l}0.995 \\
(0.829)\end{array}$ \\
\hline p-value $\left(H_{0}: \rho_{1}=1\right)$ & 0.243 & 0.133 & 0.038 \\
\hline \multicolumn{4}{|l|}{ ECM } \\
\hline$\alpha_{1}$ & $\begin{array}{c}-0.004 \\
(0.003)\end{array}$ & $\begin{array}{c}-0.004 \\
(0.003)\end{array}$ & $\begin{array}{c}-0.011^{*} \\
(0.004)\end{array}$ \\
\hline$\alpha_{0}-\alpha_{1}$ & $\begin{array}{c}-0.020^{*} \\
(0.007)\end{array}$ & $\begin{array}{c}-0.034^{*} \\
(0.015)\end{array}$ & $\begin{array}{l}0.005 \\
(0.007) \\
\end{array}$ \\
\hline AIC(MS)-AIC(linear) & -750.374 & -763.096 & -1476.168 \\
\hline SBC(MS)-SBC(linear) & -728.691 & -768.516 & -1481.588 \\
\hline HQC(MS)-HQC(linear) & -742.339 & -765.104 & -1478.176 \\
\hline
\end{tabular}

Notes: Standard errors are in parentheses; * stands for a $5 \%$ significance level. 

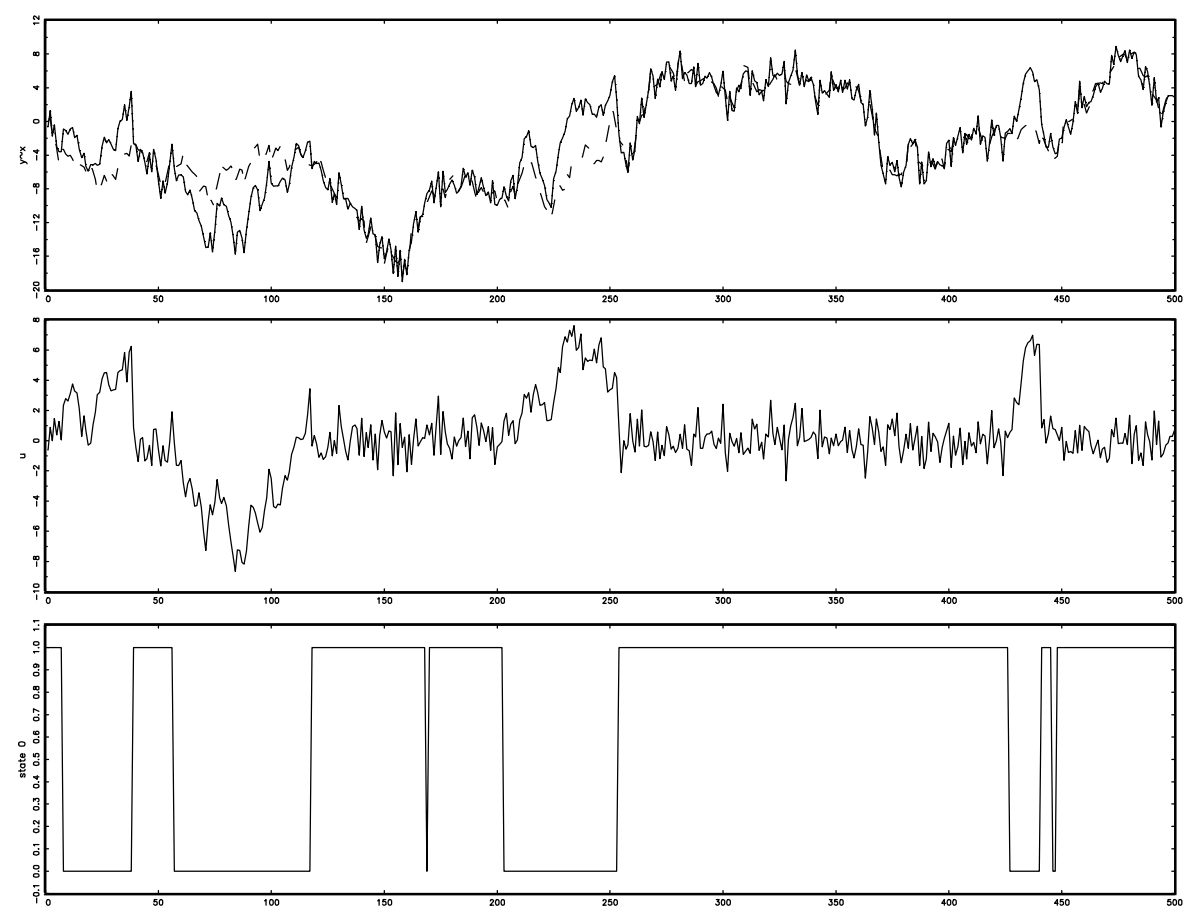

Figure 1: Top: $\left\{x_{t}, y_{t}\right\}$; Middle: $\left\{u_{t}\right\}$; Bottom: $\left\{1-s_{t}\right\}$.

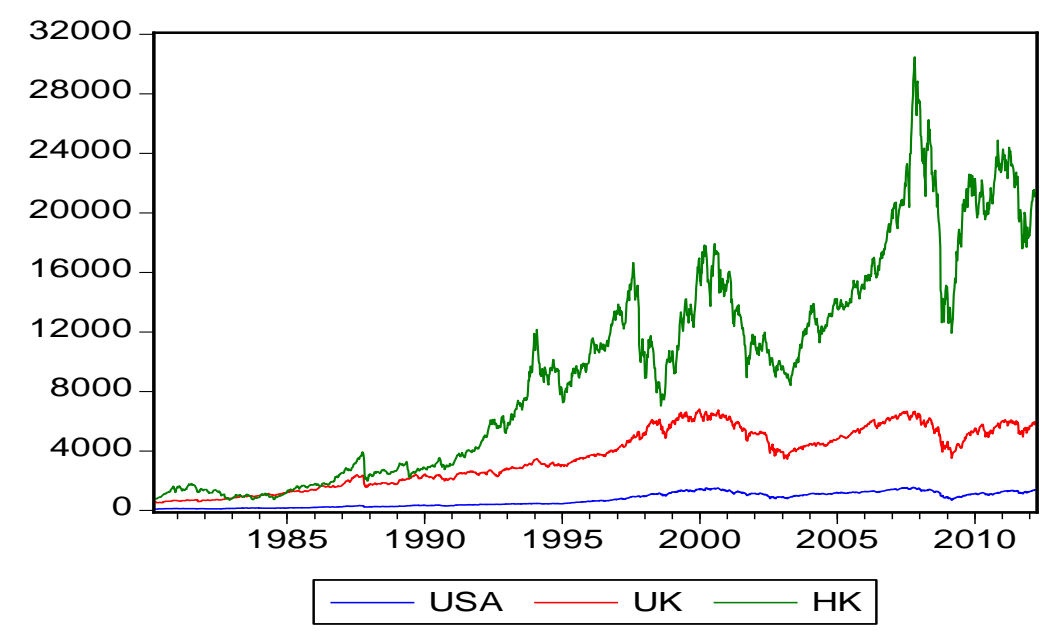

Figure 2: Financial Indices (HK - top; UK - middle; USA - bottom) 


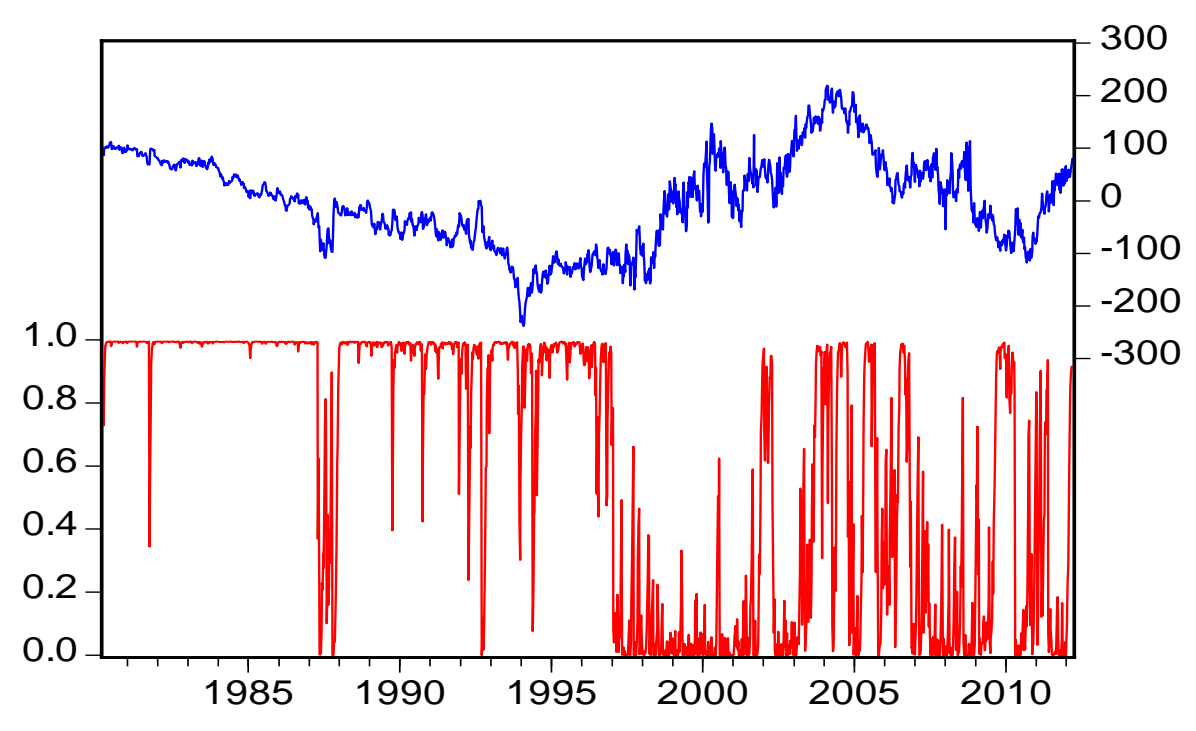

Figure 3: Interrupted Cointegration - USA

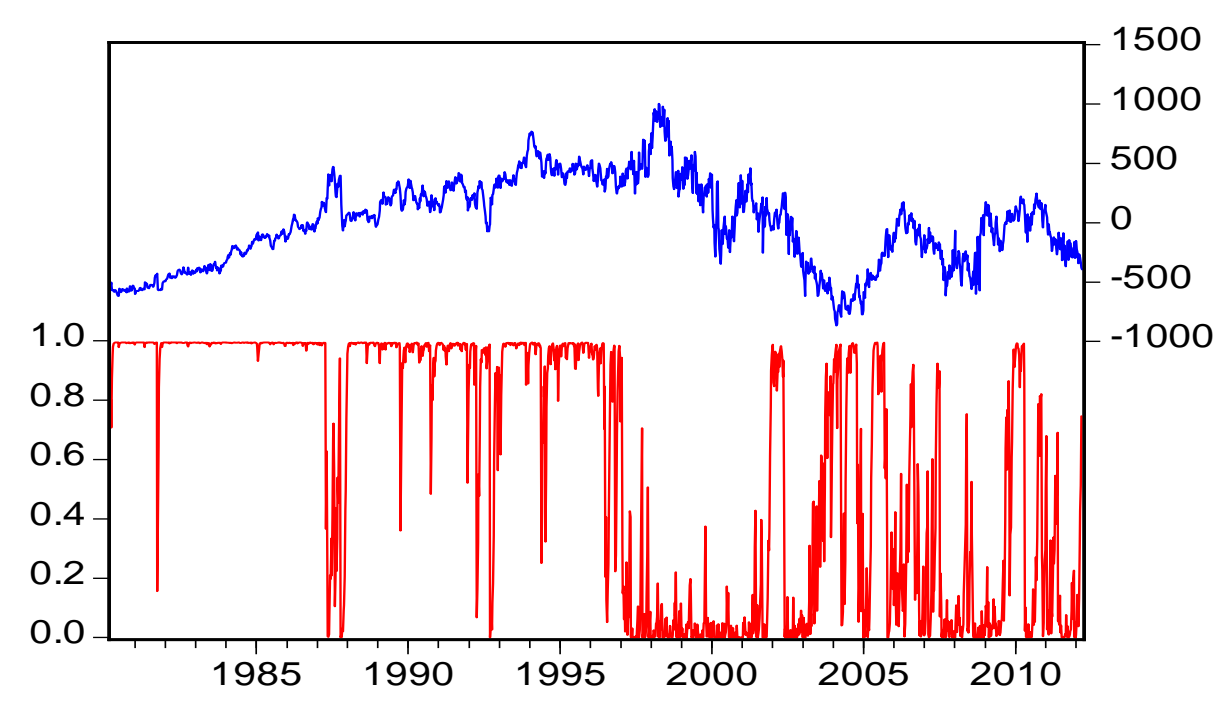

Figure 4: Interrupted Cointegration - UK 


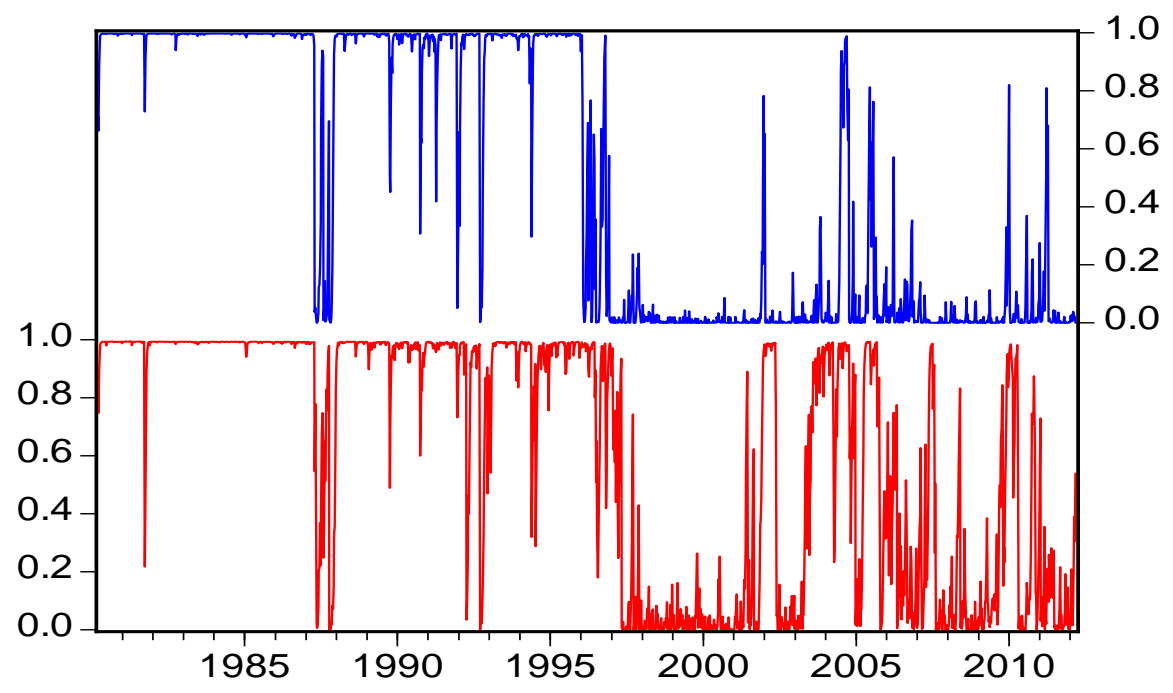

Figure 5: Estimated Probabilities of State 0 for the ECM (USA - top; UK - bottom) 